\title{
IMPROVING SURFACE QUALITY OF BEVEL Gears by Pulsed-ECH Process
}

\author{
PATHAK, S.; JAIN, N.K. \& PALANI, I.A.
}

Abstract: Improvement in surface quality of bevel gears is required to enhance their service life, operating performance and mechanical efficiency, and to reduce noise and transmission errors. Pulsed-electrochemical honing (PECH) is a fine finishing process hybridizing pulsed-electrochemical finishing (PECF) and mechanical honing. This chapter reports on improving the surface quality of $20 \mathrm{MnCr} 5$ alloy steel straight bevel gears in terms of surface finish and micro-geometry by studying effects of pulse-on time, pulse-off time and finishing time on them. The experiments were conducted using central composite design of response surface methodology by varying the each input parameter at five levels. The results have shown significant improvements in the surface quality of the PECH-finished bevel gears. Pulse-on time of $2 \mathrm{~ms}$, pulse-off time of $4.5 \mathrm{~ms}$ and finishing time of 6 minutes produced the best surface quality gear. Considerable improvement in surface integrity was also achieved which was evaluated in terms of bearing area curve, micro-structure and micro-hardness. This work proves capability of PECH for nano-finishing the gear flank surface simultaneously improving its micro-geometry and surface integrity.

Key words: PECH, bevel gears, micro-geometry, surface finish, surface integrity
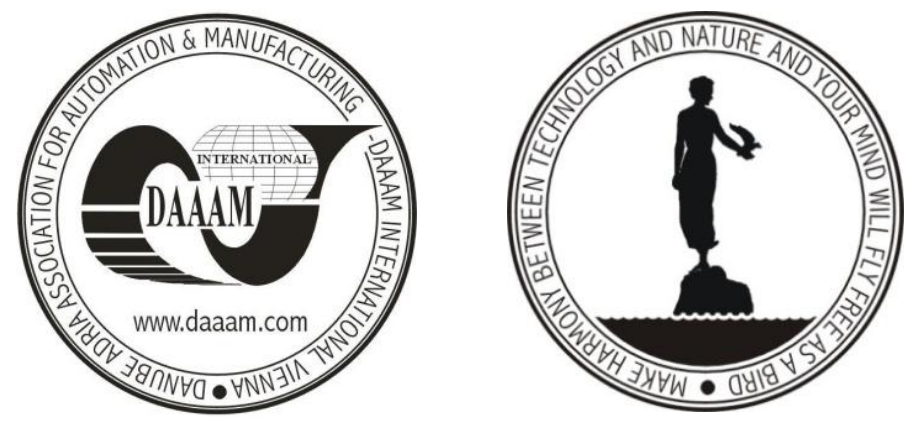

Authors' data: Pathak, S[unil]; Jain, N[eelesh] K[umar], Palani, I[yamperumal] A[nand], Discipline of Mechanical Engineering, Indian Institute of Technology Indore, 453 446, MP, India, sunilpathak87@gmail.com, nkjain@iiti.ac.in, palaniia@iiti.ac.in

This Publication has to be referred as: Pathak, S[unil]; Jain, N[eelesh] \& Palani, I[yamperumal] A[nand] (2014). Improving Surface Quality of Bevel Gears by Pulsed-Ech Process, Chapter 19 in DAAAM International Scientific Book 2014, pp.221-238, B. Katalinic (Ed.), Published by DAAAM International, ISBN 978-3901509-98-8, ISSN 1726-9687, Vienna, Austria

DOI: $10.2507 /$ daaam.scibook.2014.19 
Pathak, S.; Jain, N. \& Palani, I. A.: Improving Surface Quality of Bevel Gears by ...

\section{Introduction}

Bevel gears are used for transmitting the power and/or motion between two intersecting shafts. Pitch circle in a bevel gear lies in a cone. They are used for various applications in the fields of automobiles, avionics, shipping industries, construction machinery, agricultural equipment, machine tools and bio-medical. Bevel gear teeth profile should have very good surface finish and micro-geometry to achieve an efficient motion transmission, noiseless operation, longer service life and better operating performance. This can be ensured by improving the surface quality of the bevel gears by a suitable combination of finishing and properties enhancing processes. Gear grinding and gear lapping are the most commonly used commercial processes for bevel gear finishing. But, they suffer from their inherent limitations. Gear grinding is expensive, complicated, and may lead to undesirable effects such as grinding burns which adversely affect the surface integrity and transverse grinding lines which lead to noise and vibration during their use. While, gear lapping is a very slow process and is used to finish a conjugate pair of gears. It can rectify only minute deviations from the desired gear tooth profile moreover longer lapping cycle may affect the accuracy of gear teeth profile in a detrimental manner. These limitations can be overcome by developing a non-contact and more productive and more economical advanced fine finishing process for the gears. Pulsed-electrochemical honing (PECH) hybridizes pulsed-electrochemical finishing (PECF) and mechanical honing process in a single operation. It combines productivity and non-contact nature of PECF with micro-geometry error correction capability of mechanical honing and simultaneously overcomes their individual limitations i.e. passivation of anodic workpiece surface by formation of metallic oxide layer on it during PECF and contact and abrasive nature of mechanical honing. Consequently, PECH has capability to economically improve the surface quality and surface integrity of the bevel gears with high productivity thus meeting the above-mentioned requirements of an advanced, alternative and productive gear finishing process.

\section{Review of past work}

Capello and Bertoglio (1979) first time explored the use of ECH for finishing the hardened helical gear using specially designed helical gear as cathodic tool and $\mathrm{NaNO}_{3}$ as electrolyte Field-controlled ECH (FC-ECH) was developed by (Wei et al., 1987) to finish the spur gears by varying electric field intensity to control the electrolytic dissolution. While, (He et al., 2000) used slow-scanning field controlled ECH (SSFC-ECH) as the time-control method to correct the spur gears tooth profile errors. (Naik et al., 2008) used different combinations of $\mathrm{NaNO}_{3}$ and $\mathrm{NaCl}$ as electrolyte to finish spur gears made of EN8 by ECH and using EN24 as the honing gear material. A gravimetric aqueous solution of $\mathrm{NaCl}$ and $\mathrm{NaNO}_{3}$ in a ratio of 3:1 was used by (Misra et al., 2010) to enhance the surface finish of helical gears made of EN8 by ECH using EN24 as honing gear material. A novel idea of twin complementary cathode gears was envisaged by (Shaikh \& Jain 2013) for simultaneous fine finishing of all the teeth of a bevel gear eliminating the need to 
provide reciprocating motion to the workpiece gear. They identified applied voltage, electrolyte composition, electrolyte temperature and rotary speed of the workpiece as important ECH parameters influencing the micro-geometry and surface finish of the straight bevel gears. (Shaikh \& Jain, 2014) developed theoretical models of MRR and surface roughness of the bevel gear finished by $\mathrm{ECH}$ and experimentally validated them.

However, very limited work has been done on using derived process of PECF or its hybrid processes for improving the surface characteristics of the gears. (Pang et al., 2010) used PECF for finishing the cylindrical gears using the scanning cathode. They reported improvement in average surface roughness $\left(R_{a}\right)$ value from 3.9 to $0.35 \mu \mathrm{m}$ and modification in tooth profile by using an uneven inter-electrode gap (IEG) and modification of profile and lead by using a variable moving cathode tool. (Ning et al., 2011) also used PECF process for finishing the spiral bevel gears. But, they could finish only tooth at a time and used an indexing mechanism to finish all the gear teeth. (Misra et al., 2012) used PECH for finishing the spur gears and reported that gravimetric electrolyte composition of $75 \% \mathrm{NaCl}$ and $25 \% \mathrm{NaNO}_{3}$ and electrolyte temperature of $30^{\circ} \mathrm{C}$ yielded the best results. (Fang et al., 2014) have also mentioned that the use of pulsed current improves MRR and surface profile generated on the workpiece.

\section{Research objectives}

From the review of past work, it is evident that as of now PECH has not been explored to improve the surface quality of the straight bevel gears and no work is reported on automating the engagement and disengagement of the workpiece bevel gear with cathode and honing gears. The aim of the present research work is to bridge this gap by developing an automated experimental setup for fine finishing the straight bevel gears by PECH process and to study the effects of pulsing phenomenon in improving the surface quality and surface integrity of the PECH-finished bevel gears so as to ensure their longer service life, better operating performance, better transmission efficiency and noise reduction. Following were the objectives identified for the present research work:

1. Automation of the engagement and disengagement of the workpiece bevel gear with cathode and honing gears for better control and ease of operation.

2. To study role of pulse power supply in enhancing the process performance of $\mathrm{ECH}$ for finishing of conical gears by studying its effects on
a. Surface roughness,
b. Geometrical accuracy in terms of pitch error and runout,
c. Noise and vibration,
d. Hardness of the gear,
e. Microstructure,
f. Coefficient of friction and frictional force,
g. Residual stresses.

3. To study the effect of other PECH parameters on finishing of the conical gears. 
4. To develop theoretical models for surface roughness and MRR of conical gear finishing by PECH.

5. To develop a setup for the measurement of noise and vibration of the bevel gears.

6. To conduct plasma nitriding on honing gear and study its effects on the surface quality of the workpiece gear.

For achieving the above-mentioned objectives, the experimental setup developed by (Shaikh \& Jain 2013) for simultaneous finishing of all teeth of a straight bevel gear based on the innovative concept of twin complementary cathode gears, was modified and automated for bevel gear finishing by the PECH process. In this setup, one of the cathode gears has a conducting layer of copper sandwiched between two non-conducting layers of metalon while, other complimentary cathode gear has a non-conducting layer of metalon sandwiched between two conducting layers of copper. The conducting layers in both the complementary cathode gears are undercut by $1 \mathrm{~mm}$ than the insulating layers so as to avoid short-circuiting when these gears mesh with the workpiece gear during the finishing operation. This also ensures that IEG required for electrolytic action is maintained between the workpiece and cathode gears. $20 \mathrm{MnCr} 5$ alloy steel was chosen as a workpiece gear material due to its wide demands in automobile and aviation industries. A gravimetric aqueous solution of $75 \% \mathrm{NaNO}_{3}$ and $25 \% \mathrm{NaCl}$ was used as electrolyte (Shaikh \& Jain 2013).

Keeping in view the research objectives, the experimental investigations were planned in the three different stages namely: (i) pilot experiments, (ii) main experiments, and (iii) confirmation experiments; using design of experiment approach for each stage. Table 1 presents the summary of objectives, details of fixed and variable PECH parameters, measures of process performance or responses, and methodology of design of experiments for each stage of experimentation.

Seventeen pilot experiments were conducted using central composite design (CCD) approach of response surface methodology(RSM) to fix the pulse power supply parameters (i.e. pulse-on time, pulse-off time) and finishing time for the main experiments by studying their effects on surface quality and surface integrity of the PECH finished bevel gears. Fifty four main experiments are planned to be conducted using Box-Behnken approach of design of experiments of RSM using the fixed and variable parameters as mentioned in Table 1 . In these experiments, six important $\mathrm{PECH}$ parameters namely composition, concentration, temperature and flow rate of electrolyte, voltage and rotary speed of the workpiece gear are planned to be varied at 3 levels each to study their effects on the surface quality, surface integrity and noise and vibration characteristics of the PECH finished bevel gears. Confirmation experiments will be used to validate the results of main experiments by using the identified optimized parameters.

This chapter reports about the effects of the pulse parameters and finishing time on the surface quality and surface integrity of bevel gears. The analysis has shown significant influence of pulse-on time, pulse-off time and finishing time on measured process performance. 
Composition (by \% Wt.) of the workpiece material (i.e. 20MnCr5 alloy steel): $\mathrm{Cr}(0.8-1.1)$; $\mathrm{Mn}$ (1-1.3); $\mathrm{C}$ (0.14-0.19); P (0.035 max.); S (0.035 max.); $\mathrm{Si}$ (0.15-0.40); and balance Fe.

\begin{tabular}{|c|c|c|c|c|}
\hline $\begin{array}{l}\text { Stage of } \\
\text { experi- } \\
\text { mentatio } \\
n\end{array}$ & Objectives & Process parameters & Response & $\begin{array}{c}\text { Approach for } \\
\text { DOE and tota } \\
\text { no. of } \\
\text { experiments }\end{array}$ \\
\hline Pilot & $\begin{array}{l}\text { To find } \\
\text { optimum } \\
\text { levels of } \\
\text { PECH } \\
\text { parameters } \\
\text { which are } \\
\text { difficult to } \\
\text { change in } \\
\text { main } \\
\text { experiments }\end{array}$ & $\begin{array}{l}\text { Variable parameter } \\
\text { 1. Finishing time }(t): 5 \\
\text { levels }(3,6,9,12,15 \mathrm{~min}) \\
\text { 2. Pulse-on time }\left(T_{o n}\right): 5 \text { levels } \\
(1,2,3,4,5 \mathrm{~ms}) \\
\text { 3. Pulse-off time }\left(T_{\text {off }}\right): 5 \text { levels } \\
(3,4.5,6,7.5,9 \mathrm{~ms}) \\
\text { Fixed Parameters } \\
\text { 1. Electrolyte concentration }(\mathrm{C}) \text { : } \\
7.5 \% \text { (by wt.) } \\
\text { 2. Electrolyte temperature }(\mathrm{T}) \text { : } \\
32^{0} \mathrm{C} \\
\text { 3. Voltage }(\mathrm{V}): 12 \text { Volts } \\
\text { 4. Electrolyte composition }(\mathrm{E}) \text { : } \\
75 \% \text { NaNO }+25 \% \text { Nacl } \\
\text { 5. Electrolyte flow rate }(\mathrm{F}): 30 \mathrm{lpm} \\
\text { 6. Rotary speed of workpiece gear } \\
\text { (R): } 40 \text { rpm } \\
\text { 7. Inter-electrode gap: } 1 \mathrm{~mm}\end{array}$ & $\begin{array}{ll}\text { 1. } & P I R_{a} \\
\text { 2. } & P I R_{\max } \\
\text { 3. } & P I R_{z} \\
\text { 4. } & P I f_{p} \\
\text { 5. } & P I f_{u} \\
\text { 6. } & P I F_{p} \\
\text { 7. } & P I F_{r} \\
\text { 8. } & \text { Bearing area curve } \\
\text { 9. } & \text { SEM micrograph } \\
\text { 10. } & \text { Micro-hardness }\end{array}$ & $\begin{array}{l}\text { Response } \\
\text { surface } \\
\text { methodology } \\
\text { Centre } \\
\text { composite } \\
\text { design with } 3 \\
\text { centre points } \\
17 \text { experiments }\end{array}$ \\
\hline Main & $\begin{array}{l}\text { To study } \\
\text { the effect of } \\
\text { variable } \\
\text { parameters } \\
\text { and their } \\
\text { interactions } \\
\text { on the } \\
\text { response } \\
\text { and to } \\
\text { optimize } \\
\text { their value }\end{array}$ & $\begin{array}{l}\text { Variable parameter } \\
\text { 1. Electrolyte composition (E): } 3 \\
\text { levels }\left(100 \% \mathrm{NaNO}_{3} ;\right. \\
50 \% \mathrm{NaNO}_{3}+50 \% \mathrm{NaCl} \text { and } \\
\left.25 \% \mathrm{NaNO}_{3}+75 \% \mathrm{NaCl}\right) \\
\text { 2. Electrolyte concentration }(\mathrm{C}) 3 \\
\text { levels }(5 ; 7.5 \text { and } 10 \%)(\text { by wt. }) \\
\text { 3. Electrolyte temperature (T): } 3 \\
\text { levels }\left(27^{0} \mathrm{C} ; 32 \text { and } 37^{0} \mathrm{C}\right) \\
\text { 4. Electrolyte flow rate }(\mathrm{F}): 3 \\
\text { levels }(20 ; 25 \text { and } 30 \mathrm{lpm}) \\
\text { 5. Voltage }(\mathrm{V}): 3 \text { levels }(8 ; 12 \text { and } \\
16 \text { Volts) } \\
\text { 6. Rotary speed of workpiece gear } \\
\text { (R): } 3 \text { levels }(30 ; 40 \text { and } 50 \text { rpm) } \\
\text { Fixed Parameter } \\
\text { 1. Pulse-on time }\left(T_{\text {on }}\right):: 2 \mathrm{~ms} \\
\text { 2. Pulse-off time }\left(T_{\text {off }}\right):: 4.5 \mathrm{~ms} \\
\text { 3. Finishing time }(t): 6 \text { minutes } \\
\text { 4. Inter-electrode gap: } 1 \mathrm{~mm}\end{array}$ & $\begin{array}{l}\text { 1. } P I R_{a} \\
\text { 2. } P I R_{\max } \\
\text { 3. } P I R_{z} \\
\text { 4. } P I f_{p} \\
\text { 5. } P I f_{u} \\
\text { 6. } P I F_{p} \\
\text { 7. } P I F_{r} \\
\text { 8. MRR } \\
\text { 9. Noise \& } \\
\text { Vibration } \\
\text { characteristics } \\
\text { 10. Micro-hardness } \\
\text { 11. Bearing area } \\
\text { curve } \\
\text { 12. Wear } \\
\text { characteristics } \\
\text { 13. SEM-images } \\
\text { 14. Residual stresses }\end{array}$ & $\begin{array}{l}\text { Response } \\
\text { surface } \\
\text { methodology } \\
\text { Box-Behnken } \\
\text { design (BBD) }\end{array}$ \\
\hline $\begin{array}{l}\text { Confir } \\
\text { mation }\end{array}$ & $\begin{array}{l}\text { To confirm } \\
\text { the result of } \\
\text { the analysis } \\
\text { of main } \\
\text { experiments }\end{array}$ & $\begin{array}{l}\text { Optimum parameters given by } \\
\text { different models }\end{array}$ & $\begin{array}{l}\text { Same as main } \\
\text { experiments }\end{array}$ & 2 experiments \\
\hline
\end{tabular}

Tab. 1. Details of experimentations 
Pathak, S.; Jain, N. \& Palani, I. A.: Improving Surface Quality of Bevel Gears by ...

\section{Experimental setup}

A setup for finishing the straight bevel gears by PECH gears was developed whose schematic is shown in Fig. 1(a). This setup has four subsystems namely (i) power supply system; (ii) electrolyte supply, cleaning and recirculating system; (iii) machining chamber housing workpiece, cathode and honing gears; and (iv) A tool and motion system to provide motion to the workpiece gear.

A DC power supply system capable of supplying an output voltage in the range of $0-100$ Volts, current in the range of $10-110 \mathrm{~A}$ and with a programmable controller for setting up the values of pulse-on time in range of $(0.1 \mu$ s to $1000 \mu \mathrm{s})$, pulse-off time in range of $(1 \mathrm{~ms}$ to $1000 \mathrm{~ms})$ and duty cycle in the range of $(0-100 \%)$. The power supply can be operated either as a constant current source or as a constant voltage source. The positive terminal of the power supply is connected to the stainless steel shaft supporting the workpiece gear while the negative terminal is connected to two cathode gears through carbon brush and slip ring assembly.

The electrolyte supply, cleaning and recirculating unit consists of a stainless steel pump to supply the electrolyte at adjustable flow rate, temperature and pressure to the machining chamber. It also had flow control valves, pressure gauge, flow meter and filters. The electrolyte storage tank was fitted with a heating element to maintain the electrolyte temperature at a value above the room temperature. The electrolyte temperature was controlled by a temperature controller after sensing it by a temperature sensor. A gravimetric aqueous solution of $75 \% \mathrm{NaNO}_{3}$ and $25 \% \mathrm{NaCl}$ was used as electrolyte due to the following facts:

- $\mathrm{NaCl}$ has high corrosive nature but its conductivity is very stable over a wide range of $\mathrm{pH}$ values.

- Though, sodium nitrate $\left(\mathrm{NaNO}_{3}\right)$ is less corrosive but it creates a strong passivation layer on the workpiece, due to which less material removal rate is found in comparison with $\mathrm{NaCl}$. Due to less dissolution of anodic workpiece material better smoothness can be achieved. Also, the electrolyte reactions require higher voltage when using strong passivating electrolyte.

Therefore, to maintain the stable conductivity and clean environment in the finishing zone, an electrolyte composition of $75 \% \mathrm{NaNO}_{3}+25 \% \mathrm{NaCl}$ (by weight) was chosen for the experimentation.

Perspex sheets were used for fabricating the machining chamber as shown in fig 1(b) to provide better visibility of the PECH process and due to its better strength-toweight ratio. Pedestal type ball bearings were used to mount and support the stainless shafts on which honing and two cathode gears were mounted. Metalon blocks were used to support and mount the bearings due to its corrosion resistance, electrical insulation and higher strength-to-weight ratio. The table of the drilling machine having dimensions of $400 \mathrm{~mm} \times 400 \mathrm{~mm}$ was used to mount and support the machining chamber. The workpiece and honing gears were made of case hardened $20 \mathrm{MnCr} 5$ alloy steel and having surface hardness of 50-54 and 58-62 HRC respectively. This alloy steel was used as workpiece material because it is the most commonly used material for the production of commercial bevel gears for typical 
industrial applications. The workpiece, cathode and honing gears are straight bevel gears having module as 4.83 . The workpiece gear has 16 teeth while cathode and honing gears have 10 teeth.

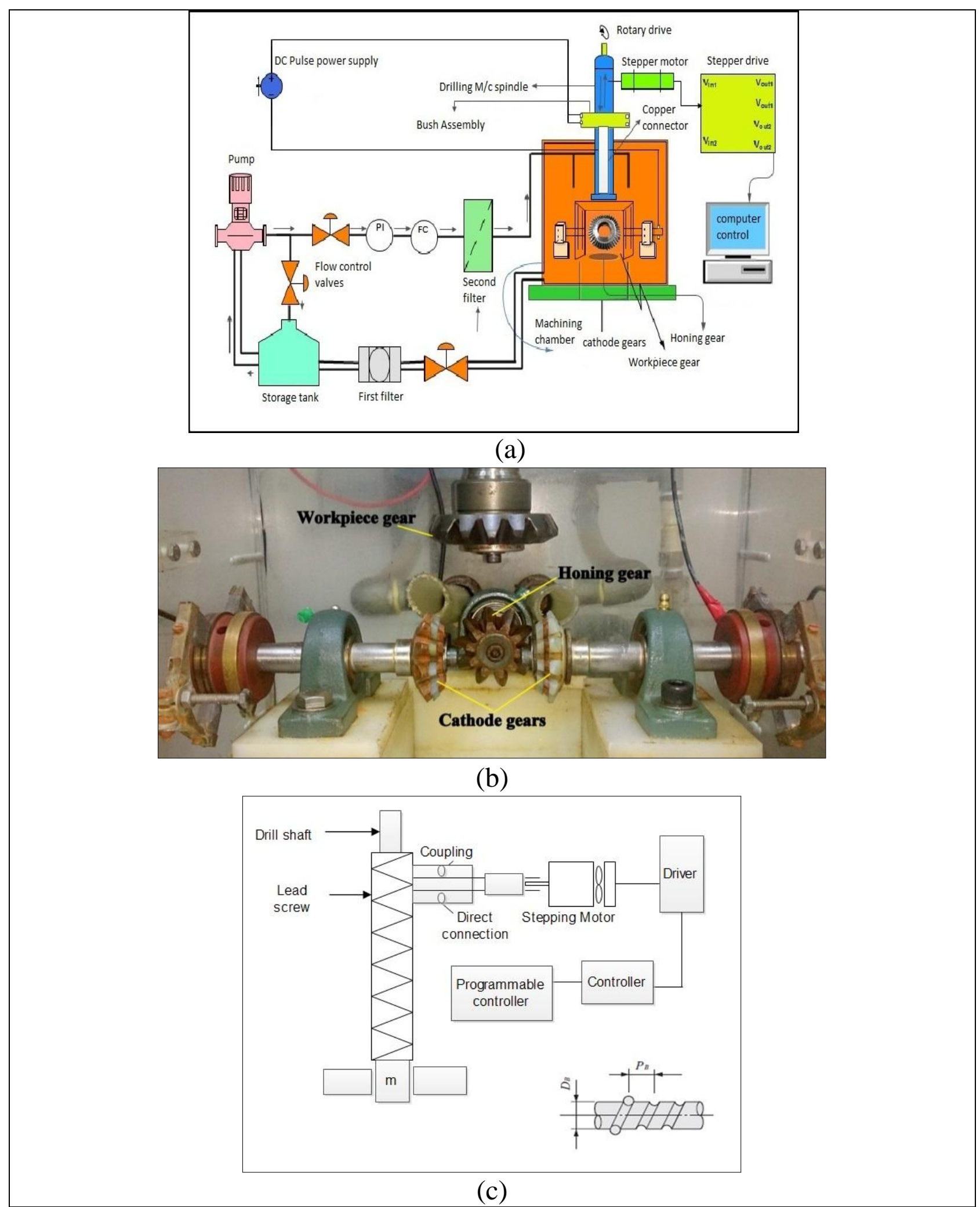

Fig. 1. Experimental setup for finishing of bevel gears by PECH: (a) schematic diagram (Pathak et al., 2013); (b) machining chamber for finishing of bevel gears by $\mathrm{PECH}$; (c) schematic of tool and motion system 
The tool and motion unit consists of an automated system for providing reciprocating motion to the spindle of the bench drilling machine which holds the workpiece gear. A stepper motor with driver and controller was used to automate the spindle of the drilling machine which is controlled by a software program by Copley Controls Corporation. This ensured higher level of accuracy in downward motion of the spindle for engagement and disengagement of workpiece gear with honing and cathode gear thus providing better control over the PECH process. This unit reciprocates the workpiece gear and makes it to engage with the honing and cathode gears for the finishing by PECH. After completing the finishing operation, it disengages the workpiece gear. Fig. 1c shows the schematic of the designed system for providing the reciprocating motion to the workpiece. Rotary motion to the workpiece gear is provided by a DC motor fixed on the frame of a drilling machine of 38-mm drilling capacity. This motor has a controller to vary the rotary speed continuously in the range of 30-1500 rpm (Pathak et al., 2013a).

\section{Experimentation}

A total of seventeen pilot experiments were conducted based on rotatable central composite design approach of RSM using Design Expert (version 8) software from Stat-Ease Inc. During these experiments, three important PECH parameters namely pulse-on time, pulse-off time and finishing time were varied at five levels each with an objective to identify their optimum values. The other parameters were kept constant. Table 2 mentions the values of the variable and fixed input parameters.

\begin{tabular}{|c|c|c|c|c|}
\hline \multirow{2}{*}{$\begin{array}{l}\text { Variable input } \\
\text { parameters }\end{array}$} & \multicolumn{3}{|c|}{ Levels } & Values of the fixed input parameters \\
\hline & $\mathbf{I}$ & II & III IV $\mathrm{V}$ & IEG: $1 \mathrm{~mm}$; Voltage:12V \\
\hline $\begin{array}{l}\text { Pulse-on time, } T_{o n} \\
\text { (ms) }\end{array}$ & 1 & 2 & $\begin{array}{lll}3 & 4 & 5\end{array}$ & $\begin{array}{l}\text { Electrolyte composition: } 75 \% \mathrm{NaNO}_{3}+25 \\
\% \mathrm{NaCl}\end{array}$ \\
\hline $\begin{array}{l}\text { Pulse-off time, } T_{\text {off }} \\
\text { (ms) }\end{array}$ & 3 & 4.5 & 67.59 & $\begin{array}{l}\text { Electrolyte concentration: } 7.5 \mathrm{wt} . \% \\
\text { Electrolyte temperature: } 32^{\circ} \mathrm{C}\end{array}$ \\
\hline $\begin{array}{l}\text { Finishing time, } \mathrm{t} \\
\text { (minutes) }\end{array}$ & & 6 & 91215 & $\begin{array}{l}\text { Electrolyte flow rate: } 301 \mathrm{pm} \\
\text { Rotary speed of workpiece gear: } 40 \mathrm{rpm}\end{array}$ \\
\hline
\end{tabular}

Tab. 2. Values of the variable and fixed input parameters (Pathak et al. 2014a)

The investigations were focused: (i) to improve the surface finish expressed in terms of average percentage improvement in average surface roughness $\left(P I R_{a}\right)$, in maximum surface roughness $\left(P I R_{\max }\right)$ and in depth of surface roughness $\left(P I R_{z}\right)$; (ii) to enhance the accuracy in micro-geometry of straight bevel gears in terms of average percentage improvements in single pitch error $\left(P I f_{p}\right)$, in adjacent pitch error $\left(P I f_{u}\right)$, in cumulative pitch error $\left(P I F_{p}\right)$ and percentage improvement in total runout $\left(P I F_{r}\right)$; (iii) to identify the optimum pulse parameters and finishing time for the future investigations; (iv) to analyze the bearing area curve for the unfinished gear and for PECH-finished gear at the identified optimum parameters; (v) to analyze the microstructure and micro-hardness of the gear finished by PECH at optimum parameters and their comparison with the unfinished gear. 
Surface roughness parameters $\left(R_{a}, R_{\max }\right.$ and $\left.R_{z}\right)$ were evaluated using the contracer-cum-surface roughness analyzer (model SEF 3500) from Kosaka Japan. Two measurements, one on the left-hand profile and other on the right-hand profile, both at the middle of the face width of two consecutive gear teeth were taken before and after finishing the bevel gears by PECH using evaluation length of $1.6 \mathrm{~mm}$ and cut-off length of $0.8 \mathrm{~mm}$. Arithmetic mean of these four values of a surface roughness parameter was used to compute percentage improvements in it i.e. percentage improvement in average surface roughness ' $P I R_{a}$ ' was calculated using eq. 1.

$$
\text { Avg.PIR } R_{a}=\frac{\text { Avg.PIR } a v a l u e \text { before } P E C H-\text { Avg.PIR } a \text { value after } P E C H}{A v g \cdot P I R_{a} \text { value before } P E C H}
$$

Similarly average values of $P I R_{\max }$ and $P I R_{z}$ were computed using their corresponding average values. Micro-geometry was evaluated in terms of average percentage improvement in single pitch error $f_{p}$, in adjacent pitch error $f_{u}$, in cumulative pitch error $F_{p}$ and percentage improvement in total runout $F_{r}$. These micro-geometry parameters of straight bevel gears were investigated using CNC gear metrology machine SmartGear 500 from Wenzel GearTec, Germany. For each experiment, the measurement were taken on left hand (LH) and right hand (RH) flanks of all the 16 teeth of a gear before and after its finishing by $\mathrm{PECH}$. Average values of the corresponding parameter were used to compute average percentage improvements in these parameters i.e. $\operatorname{PIf}_{p}, P I f_{u}, P I F_{p}$ and percentage improvements in $P I F_{r}$ using the concept used in the eq. 1. A higher value of percentage improvement in a surface roughness and micro-geometry parameter indicates smaller value of that parameter after finishing the bevel gear by PECH.

Micro-hardness and microstructure were studied for the unfinished gear and the gear finished by $\mathrm{PECH}$ at optimized parametric combination. Vicker's microhardness was tested at a load of $0.5 \mathrm{~kg}$ and dual time 15 seconds using the microhardness tester (model VMH-002) from Walter UHL, Germany. The changes in the microstructure of the bevel gear tooth flank surface before and after finishing by PECH were studied through scanning electron microscopic (SEM) images obtained by FE-SEM (model Supra 55) from Carl Zeiss Germany.

\section{Results and discussion}

Table 3 presents the averages values of all the responses for the seventeen experiments. It can be observed from these results that the best combination of responses was achieved for experiment no. 11 having input parameters $T_{o n}$ as $2 \mathrm{~ms}$; $T_{\text {off }}$ as $4.5 \mathrm{~ms}$ and $t$ as 6 minutes. It yielded average values of surface roughness parameters i.e. $P I R_{a}, P I R_{\max }$ and $P I R_{z}$ equal to $47.3 \%, 46.2 \%$, and $34.2 \%$ respectively. It also gave the average values of the micro-geometry parameters $\operatorname{PIf}_{p}, \operatorname{PIf}_{u}, \operatorname{PIF}_{p}$ and $P I F_{r}$ as $34.2 \%, 39.6 \%, 13.3 \%$ and $18.9 \%$ respectively. These values are the maximum values for $P I R_{a}, P I R_{\max }, P I f_{p}, P I f_{u}$, and $P I F_{p}$ and $4^{\text {th }}$ best value for $P I F_{r}$ and $8^{\text {th }}$ best 
Pathak, S.; Jain, N. \& Palani, I. A.: Improving Surface Quality of Bevel Gears by ...

value for $P I R_{z}$. The maximum value of $P I R_{z}$ and $P I F_{r}$ was obtained for the experiment no. 15 and 7 respectively but it resulted in very low values of other five responses. Micro-hardness test revealed no major change before and after finishing by $\mathrm{PECH}$.

\begin{tabular}{|ccccccccccc|}
\hline \multicolumn{1}{c}{ Input variables } & \multicolumn{7}{c|}{ Average values of the responses } \\
\hline $\begin{array}{c}\text { Run } \\
\text { no. }\end{array}$ & $\begin{array}{c}T_{\text {on }} \\
(\mathrm{ms})\end{array}$ & $\begin{array}{c}T_{\text {off }} \\
(\mathrm{ms})\end{array}$ & $\begin{array}{c}t \\
(\mathrm{~min})\end{array}$ & $P I R_{a}$ & $P I R_{\max }$ & $P I R_{z}$ & $P I f_{p}$ & $P I f_{u}$ & $P I F_{p}$ & $P I F_{r}$ \\
\hline 1 & 3 & 6 & 9 & 10 & 36.4 & 34.1 & -7.4 & -7.9 & -10.2 & -21.6 \\
\hline 2 & 3 & 6 & 9 & 17.4 & 17.1 & 21.7 & 1.4 & -4.1 & -2.2 & 3.3 \\
\hline 3 & 1 & 6 & 9 & -9 & 45.6 & 6.96 & -4.5 & 11.5 & -11.2 & -3.7 \\
\hline 4 & 4 & 4.5 & 12 & 21.7 & 26.3 & 26.7 & 18.5 & 28.1 & -1.9 & -10.7 \\
\hline 5 & 2 & 7.5 & 12 & 34.1 & 4.9 & 42.7 & -5.2 & 10.0 & -35.3 & -11.5 \\
\hline 6 & 4 & 4.5 & 6 & 25.4 & 18.2 & 48.1 & 14.8 & 37.8 & 5.7 & 28.8 \\
\hline 7 & $\mathbf{3}$ & $\mathbf{3}$ & $\mathbf{9}$ & $\mathbf{3 2 . 6}$ & $\mathbf{9 . 1}$ & $\mathbf{4 1 . 9}$ & $-\mathbf{- 0 . 5}$ & $\mathbf{1 4 . 4}$ & $\mathbf{- 3 . 9}$ & $\mathbf{4 8 . 2}$ \\
\hline 8 & 2 & 7.5 & 6 & -10.1 & -1.04 & 1.2 & 8.9 & -15.7 & 9.4 & -6.3 \\
\hline 9 & 5 & 6 & 9 & 24.9 & 31.7 & 41.9 & -4.6 & -13.2 & -1.8 & -7.8 \\
\hline 10 & 2 & 4.5 & 12 & 40.1 & -7.4 & 43.9 & 2.8 & 10.1 & -10.9 & 18.9 \\
\hline $\mathbf{1 1}$ & $\mathbf{2}$ & $\mathbf{4 . 5}$ & $\mathbf{6}$ & $\mathbf{4 7 . 3}$ & $\mathbf{4 6 . 9}$ & $\mathbf{3 4 . 2}$ & $\mathbf{3 4 . 2}$ & $\mathbf{3 9 . 6}$ & $\mathbf{1 3 . 3}$ & $\mathbf{1 8 . 9}$ \\
\hline 12 & 3 & 6 & 9 & 18.5 & 22.8 & 19.3 & 9.1 & 7.3 & 5.4 & 15.7 \\
\hline 13 & 4 & 7.5 & 6 & 21.2 & 3.9 & 27.1 & -1.4 & 0.6 & 11.5 & 10.2 \\
\hline 14 & 3 & 9 & 9 & 16.7 & 16.7 & 8.1 & -1.8 & 2.7 & -12.4 & -8.7 \\
\hline $\mathbf{1 5}$ & $\mathbf{3}$ & $\mathbf{6}$ & $\mathbf{3}$ & $\mathbf{3 9 . 7}$ & $\mathbf{2 5 . 1}$ & $\mathbf{5 5 . 5}$ & $\mathbf{1 3 . 1}$ & $\mathbf{2 . 8}$ & $\mathbf{1 1 . 6}$ & $\mathbf{6 . 5}$ \\
\hline 16 & 3 & 6 & 15 & -13.4 & 21.8 & 8.8 & -2.3 & -5.4 & -12.9 & 5.0 \\
\hline 17 & 4 & 7.5 & 12 & 29.1 & 35.6 & 41.2 & -12.4 & -1.9 & -4.2 & 4.6 \\
\hline
\end{tabular}

Tab. 3. Average values of the percentage improvement in the parameters of surface roughness $\left(P I R_{a}, P I R_{\max }\right.$ and $\left.P I R_{z}\right)$ and micro-geometry $\left(P I f_{p}, P I f_{w}, P I F_{p}\right.$, and $\left.P I F_{r}\right)$ for different experimental runs

\subsection{Analysis of surface quality}

Fig. 2 depicts variation in average values of $P I R_{a}$ and $P I R_{\max }$ with pulse-on time (Fig. 2a), pulse-off time (Fig. 2b) and finishing time (Fig. 2c) showing the range (shown as vertical bars) and average of their experimental values at a particular level of an input parameter. The predicted values of $a v g . P I R_{a}$ and $a v g . P I R_{\max }$ (using Eqn. 2 and 3) are shown by the linear graphs. It can be observed from these figures the optimum range of $T_{o n}, T_{\text {off }}$ and $t$ exist for the maximum values of $a v g . P I R_{a}$, and $a v g$. $P I R_{\max }$ because the maximum experimental values of $a v g . P I R_{a}$ and $a v g . P I R_{\max }$ occurred for $T_{\text {on }}$ values in range of 1-2 ms (Fig. 2a); for $T_{\text {off }}$ values in the range of 4.5$6 \mathrm{~ms}$ (Fig. 2b) and for $t$ values in the range of 3-9 minutes (Fig. 2c). 


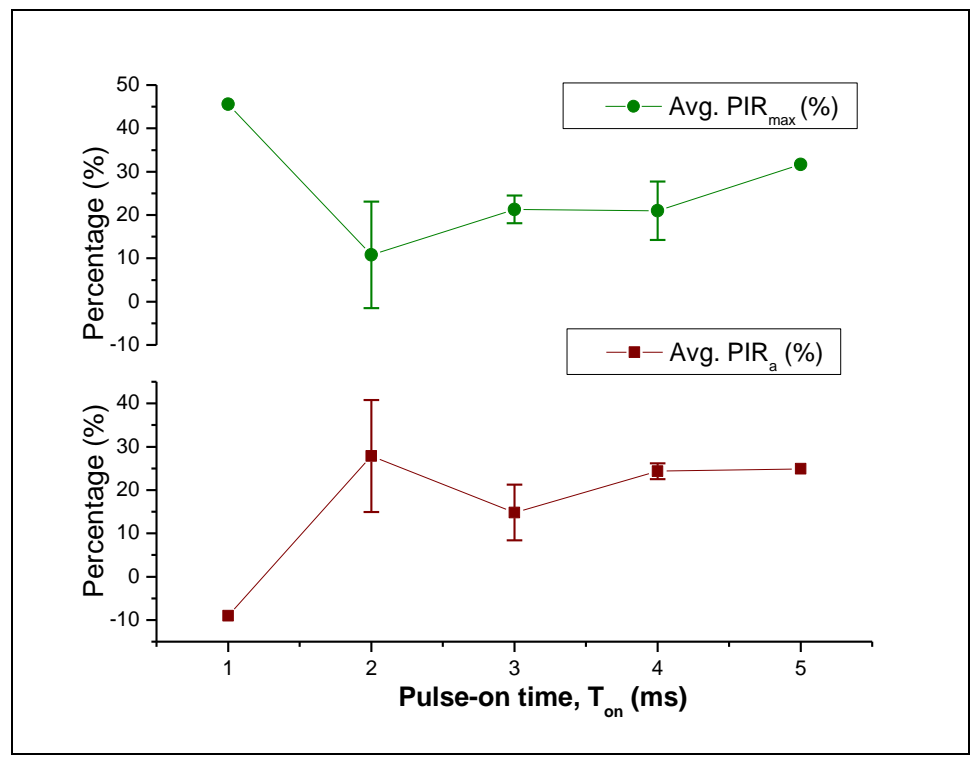

(a)

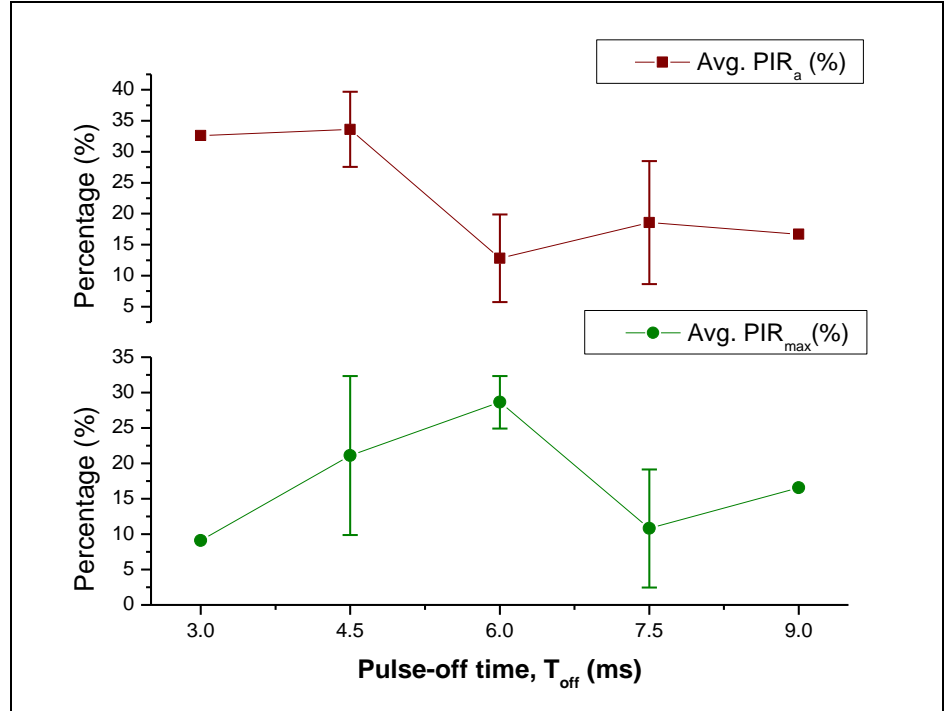

(b)

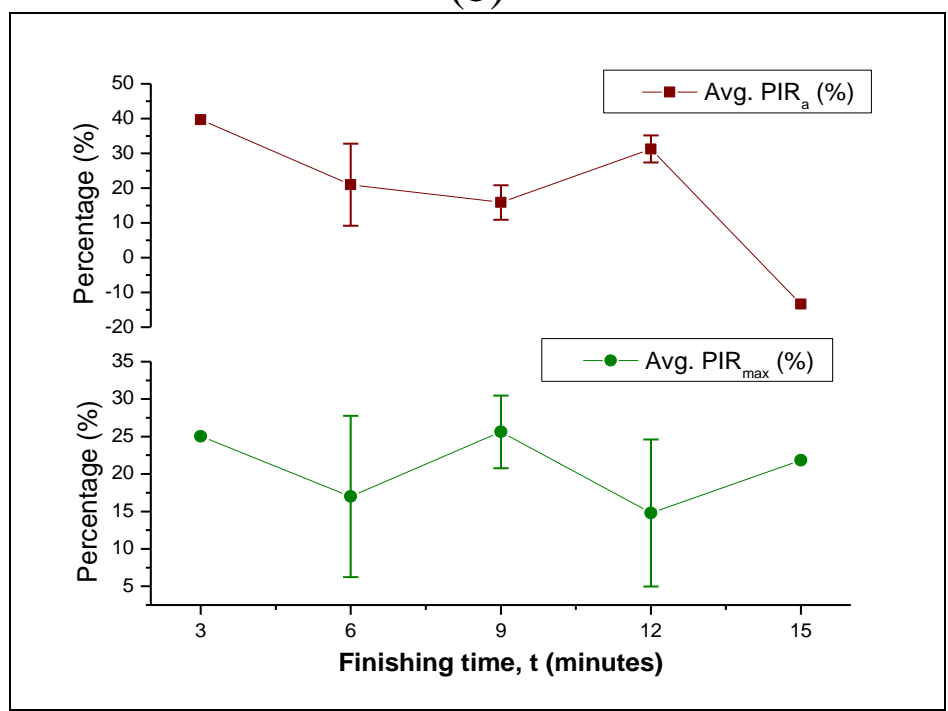

(c)

Fig. 2. Variation of $P I R_{a}$ and $P I R_{\max }$ with (a) pulse-on time $\left(T_{o n}\right)$; (b) pulse-off time $\left(T_{\text {off }}\right)$; and (c) finishing time $(t)$ (Pathak et al. 2014b) 
Pathak, S.; Jain, N. \& Palani, I. A.: Improving Surface Quality of Bevel Gears by ...

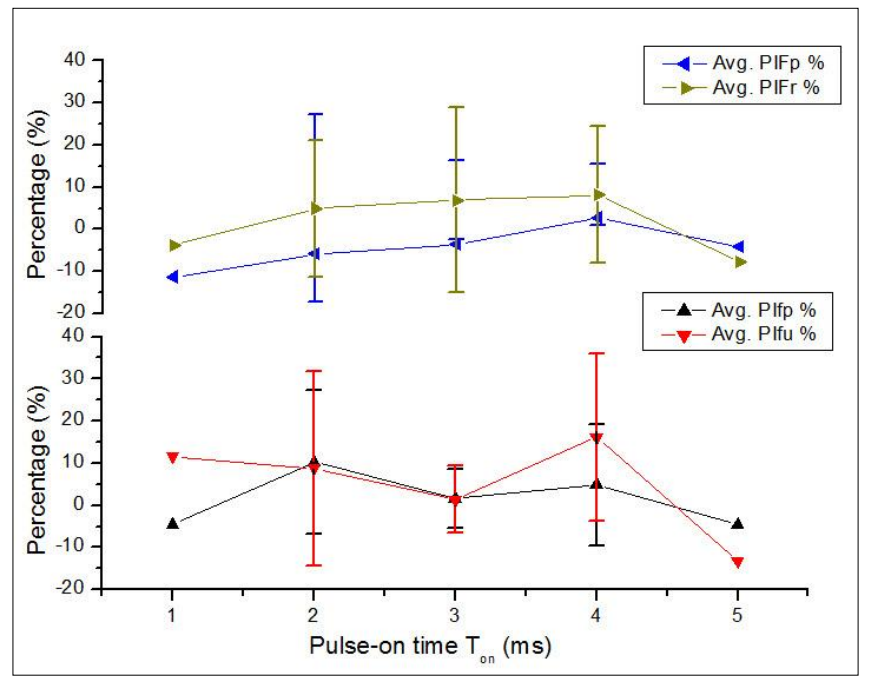

(a)

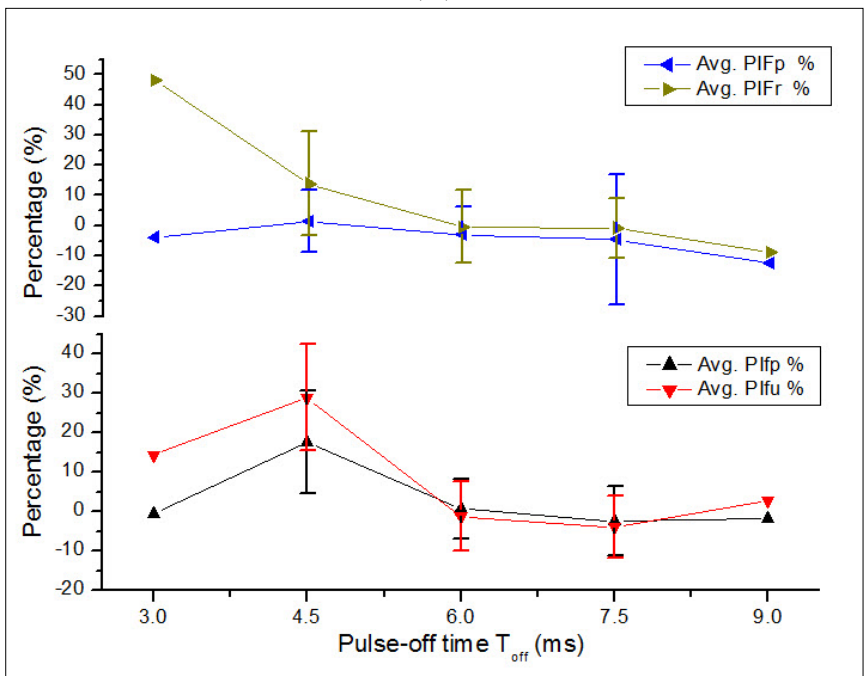

(b)

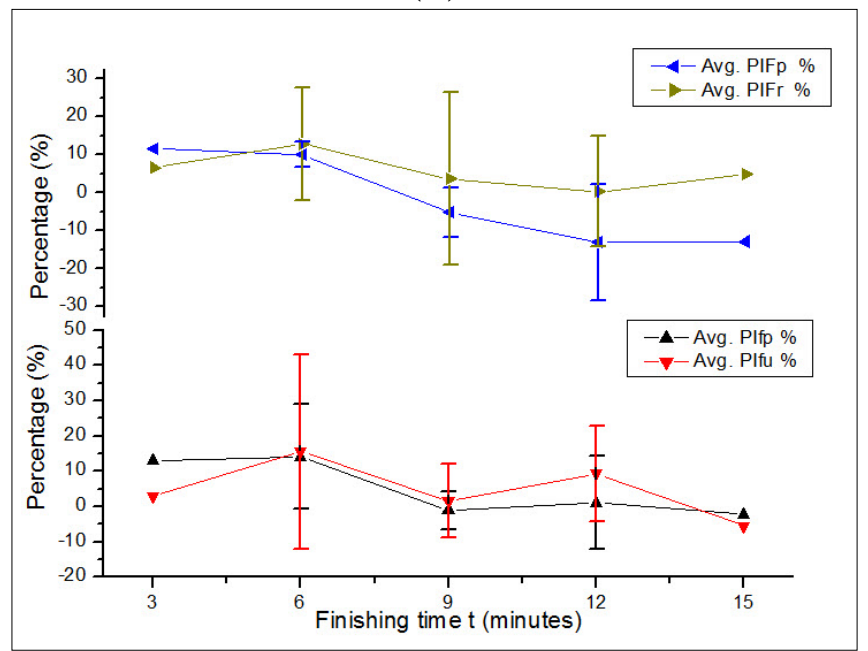

(c)

Fig. 3. Variation of percentage improvements in single pitch error $\left(P I f_{p}\right)$, in adjacent pitch error $\left(P I f_{u}\right)$, in cumulative pitch error $\left(P I F_{p}\right)$ and in total runout $\left(P I F_{r}\right)$ with (a) pulse-on time; (b) pulse-off time; and (c) finishing time (Pathak et al. 2014a) 
It can be seen from Fig. $3 \mathrm{a}$ that values of average percentage improvements in single pitch error $\left(P I f_{p}\right)$, adjacent pitch error $\left(P I f_{u}\right)$, cumulative pitch error $\left(P I F_{p}\right)$ and total runout $\left(P I F_{r}\right)$ attain their maximum values for pulse-on time in the range of 2-4 ms. It is evident from Fig. $3 b$ that average values of percentage improvements in single pitch error, adjacent pitch error and cumulative pitch error attain their maximum values at pulse-off time equal to $4.5 \mathrm{~ms}$ whereas, value of total runout attains its peak value at pulse-off time of 3 ms. Finishing time of 6 minutes (Fig. 3c) resulted in attaining maximum values for average values of percentage improvements in single pitch error $\left(P I f_{p}\right)$, adjacent pitch error $\left(P I f_{u}\right)$, cumulative pitch error $\left(P I F_{p}\right)$ and total runout $\left(P I F_{r}\right)$.

The above trends in Surface roughness and micro-geometry parameters can be justified by the following facts:

- In PECH, inclusion of pulse-on time decreases the concentration polarization effect (i.e. concentration polarization is the formation of diffusion layer on the anode surface which acts as barrier), due to which a higher peak voltage is required to break this barrier, it helps in decreasing the dissolution and enhancing the surface finish of the workpiece material. But, a sufficient amount of pulse-on time is needed so that the anode (i.e. workpiece gear) gets sufficient energy to initiate the dissolution process. Thus, from the obtained trends it was depicted that a higher value of pulse-on time will lead to more electrolytic dissolution of workpiece gear material and generating more quantity of electrolytic reaction products and deteriorates the surface quality of the gears due to increased MRR and poor flushing of the reaction products. According to Faraday's law; application of high voltage increases the current density which leads to higher dissolution of workpiece material i.e. higher MRR, which adversely affects the surface profile.

- Lower value of pulse-off time leads to inefficient flushing of the electrolytic reaction products from IEG which ensure clean environment in the IEG without any clogging. While very high value means very less finishing action. Higher pulse-off time adversely affects the surface roughness of bevel gears due to reduced finishing time available for the anodic dissolution of workpiece gear.

- Higher finishing time deteriorates the surface profile of the bevel gears due to anodic dissolution of workpiece gear material for longer duration giving poor surface finish.

The reports generated by the $\mathrm{CNC}$ gear metrology machine for single pitch error and adjacent pitch error for left hand (LH) flank of the straight bevel gear before and after its finishing by $\mathrm{PECH}$ for the best finished gear at optimized parameters are shown in fig. $4 \mathrm{a}$ and $4 \mathrm{~b}$ present. Fig. $5 \mathrm{a}$ and $5 \mathrm{~b}$ present the same for the cumulative pitch error and total runout. It can be seen from the figures $4 a-4 b$ that percentage improvement in single pitch error $\left(P I f_{p}\right)$ and percentage improvement in adjacent pitch error $\left(P I f_{u}\right)$ for LH flank are $60.75 \%$ and $65.5 \%$ respectively. This improves the quality of the gears from DIN standard 9 to DIN 7 for $f_{p}$ and DIN10 to DIN 7 for $f_{u}$ of LH flank of the gear. From fig. 5a and 5b, the percentage improvements obtained in cumulative pitch error $\left(P I F_{p}\right)$ and in total runout $\left(P I F_{r}\right)$ for LH flank are $27 \%$ and $18.9 \%$ respectively. This improves the gear quality from DIN standard 8 to 7 for $F_{p}$ while no change in DIN standard for $F_{r}$. 
Pathak, S.; Jain, N. \& Palani, I. A.: Improving Surface Quality of Bevel Gears by ...

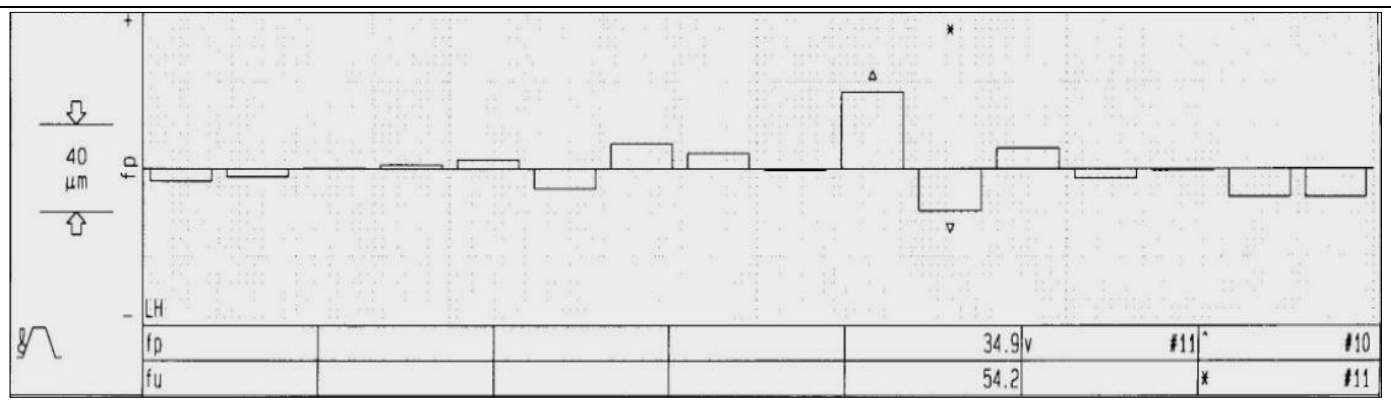

(a)

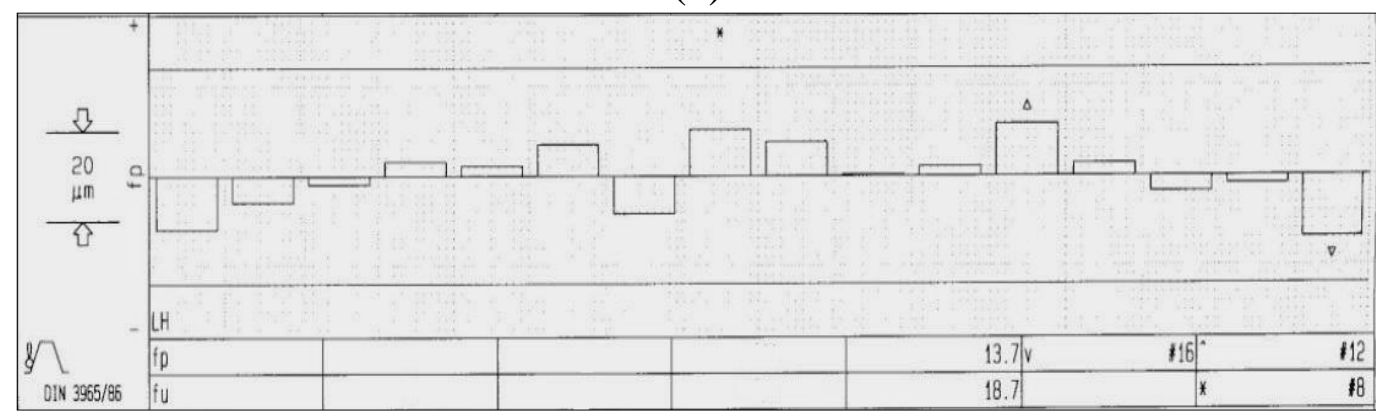

(b)

Fig. 4. Single pitch error ' $f_{p}$ ' and adjacent pitch error ' $f_{u}$ ' of bevel gear tooth for the identified optimum PECH parameters: (a) before PECH and (b) after PECH (Pathak et al. 2014a)

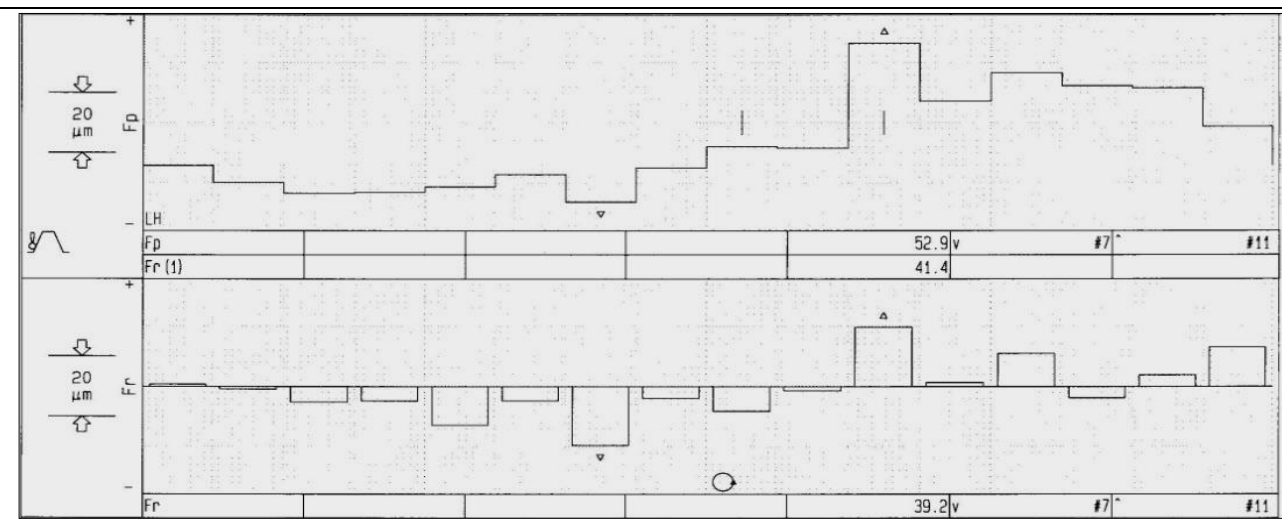

(a)

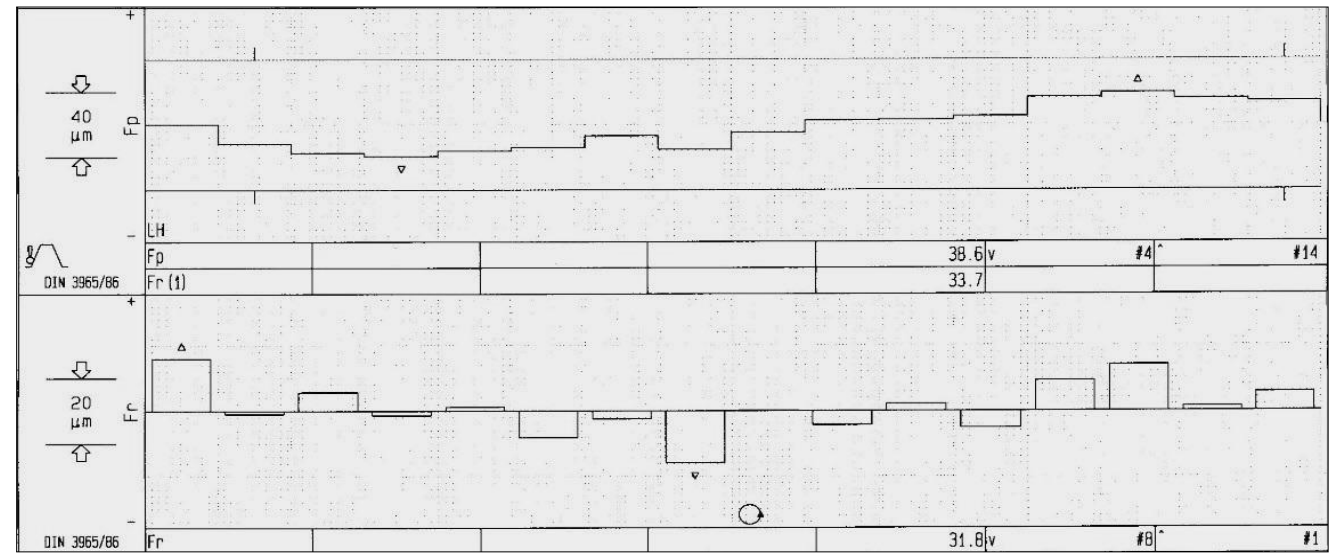

(b)

Fig. 5. Cumulative pitch error ' $F_{p}$ ' and total runout ' $F_{r}$ ' of straight bevel gear tooth for the identified optimum PECH parameters: (a) before PECH and (b) after PECH (Pathak et al. 2014a) 


\subsection{Analysis of microstructure}

Figs. 6(a-b) depict the SEM images of an unfinished gear tooth and a gear finished by $\mathrm{PECH}$ at optimum input parameters at 500X magnification. It can be observed from these SEM images that roughness and scratches are smoothened, micro-pits are removed and porosity of the workpiece material becomes visible after finishing by PECH. This smoothing results in quieter operation as well as enhanced service life of the bevel gears.

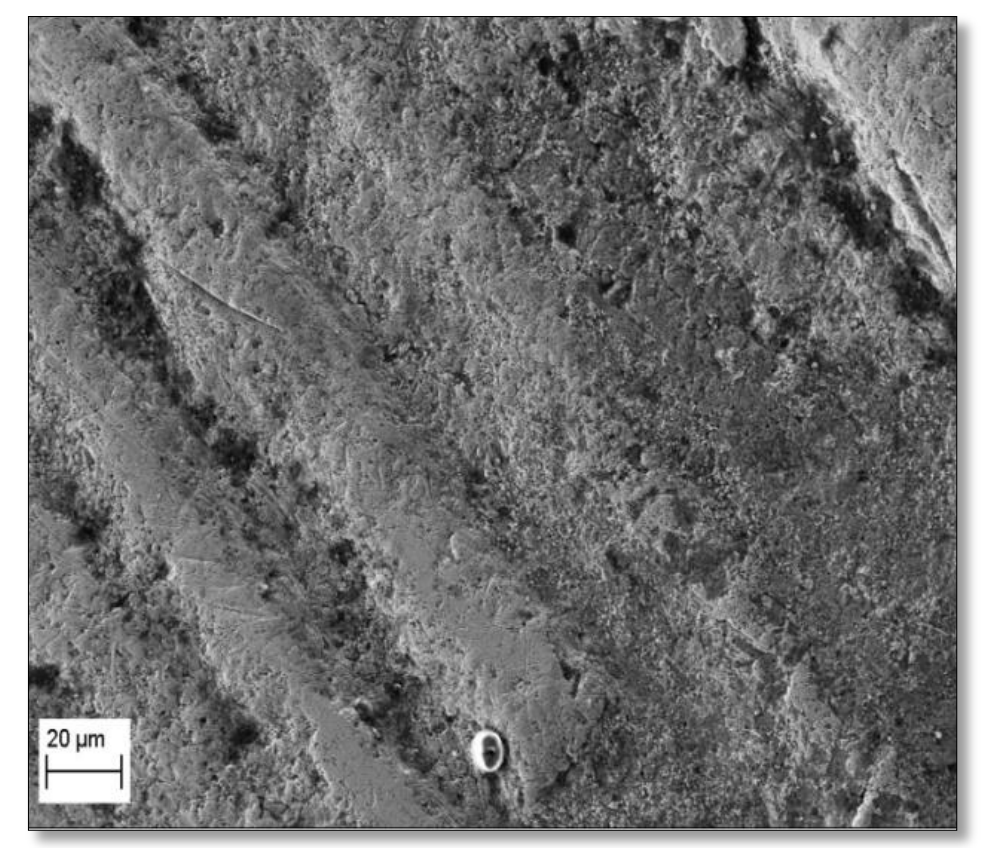

(a)

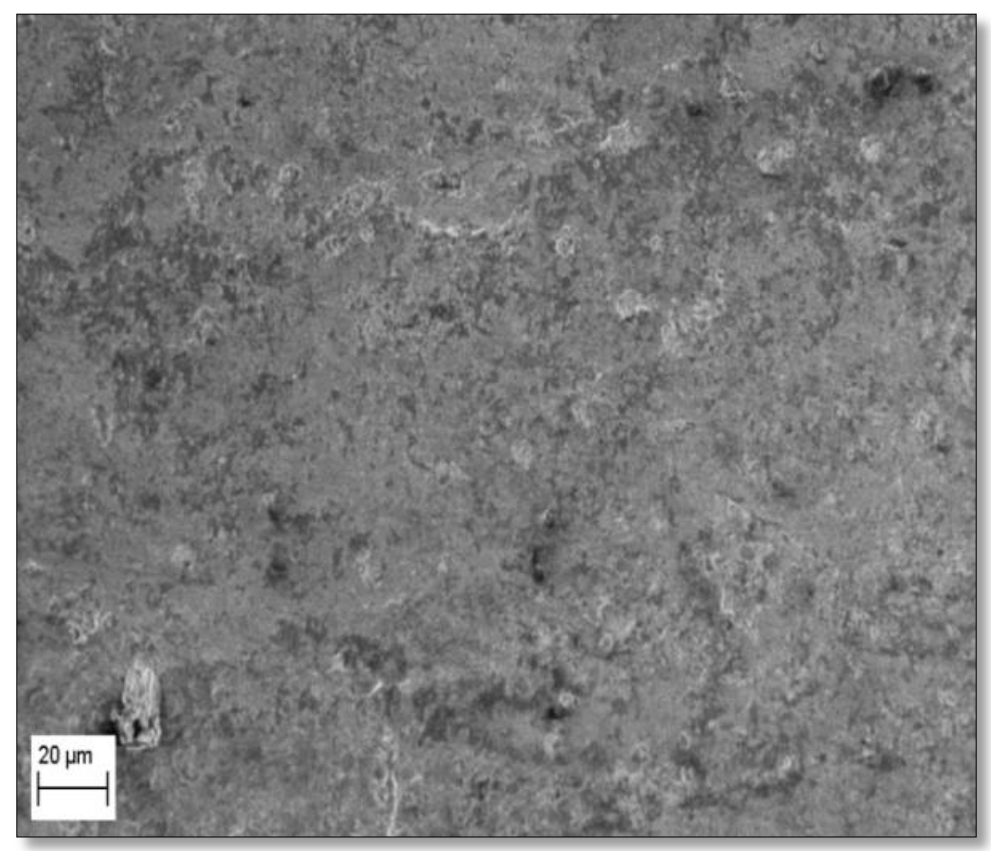

(b)

Fig. 6. SEM images of gear tooth flank surface at 500Xmagnification (a) unfinished gear; and (b) gear finished by PECH using the identified optimum input parameters 


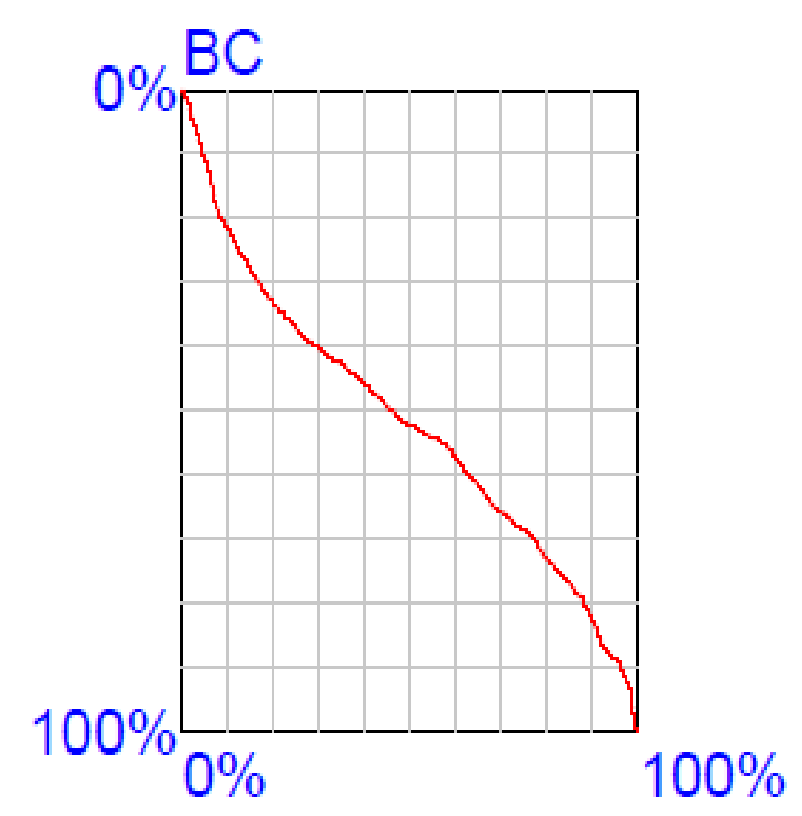

(a)

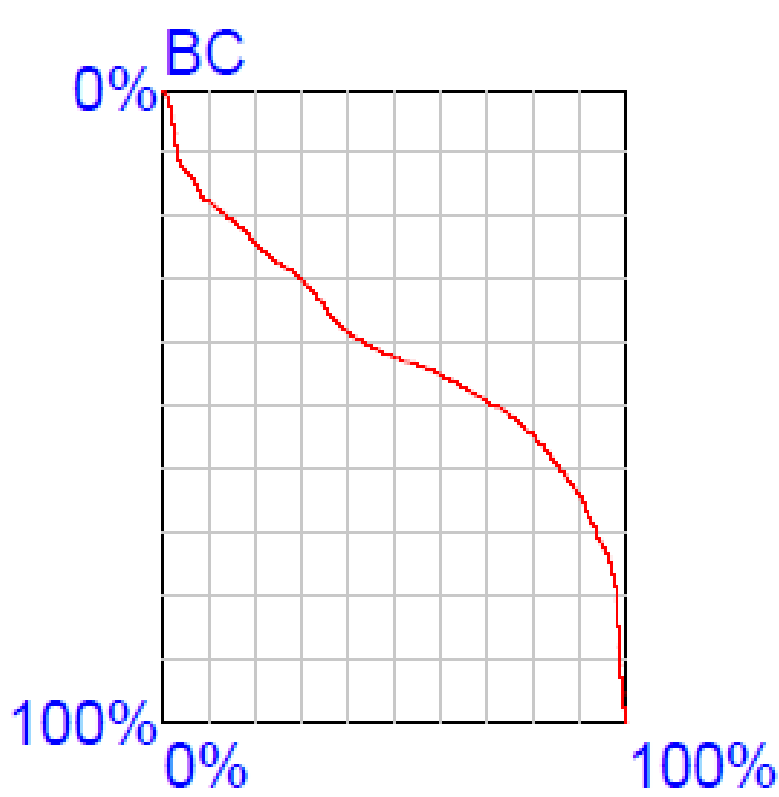

(b)

Fig. 7. Bearing area curve on the gear surface (a) before PECH; (b) after PECH

Figures $7(a-b)$ depict the variations in the bearing area curve (BAC) before and after finishing the bevel gears by $\mathrm{PECH}$. The improvement in BAC after PECH results in larger contact area which results in better contact ratio, providing enhanced transmission accuracy and hence less noise and vibration during the operation. Micro-hardness values before (i.e. unfinished) and after finishing the bevel gear by the PECH for an optimum duration of 6 minutes was evaluated. It was found from these results that at any particular location Vicker's hardness values of the unfinished and PECH finished gear are almost same.Hence, it can be conclude that the finishing of bevel gears by PECH will not affect its surface integrity.

\section{Conclusions}

The present work involved investigation on the influence of pulse-on time, pulse-off time and finishing time on the surface quality and surface integrity of the straight bevel gears finished by PECH process with an objective to optimize PECH parameters for the future work. Following conclusions can be drawn from this work:

- Pulse-on time $\left(T_{o n}\right)$, pulse-off time $\left(T_{o f f}\right)$, and finishing time (t) are found to be the most important parameter in enhancing the surface characteristics of the straight bevel gears finished by the PECH process. The optimum values of parameters identified are $T_{\text {on }}$ as $2 \mathrm{~ms} ; T_{\text {off }}$ as $4.5 \mathrm{~ms}$ and (giving duty cycle of $30.77 \%)$ and $t$ as 6 minutes.

- The pulse-on time should be less than the pulse-off time so as to enable removal of the electrolytic reaction products formed during the pulse-on time and keep the IEG clean for the next cycle of workpiece dissolution.

- Use of the identified optimum PECH parameters yielded the average values of $P I R_{a}$ as $47.35 \%$; PIR $\max$ as $46.92 \%$ and $P I R_{z}$ as $34.2 \%$. Improvements in 
roughness parameters helps in better service life, improved operating performance, reduced noise and transmission error of the straight bevel gears.

- It also improved the micro-geometry of the straight bevel gear yielding average values of $P I f_{p}, P I f_{u}$ and $P I F_{p}$ equal to $34.2 \% ; 39.6 \%$ and $13.3 \%$ respectively and $P I F_{r}$ as $18.9 \%$. This improves the gear quality up to DIN 7 standard which is same as that given by the bevel gear grinding process. Better micro-geometry accuracy reduces the noise and transmission related error.

- Improvements obtained by PECH in surface finish and micro-geometry of the straight bevel gears are much better than those obtained by (Shaikh \& Jain 2013) using ECH and by (Ning et al., 2011) using PECF.

- PECH also improves the micro-structure of the finished gear while it does not affect the micro-hardness of the finished gear.

- The accuracy achieved by PECH is free from both mechanical and thermal and related distortions unlike the gears finished by the gear grinding process because majority of finishing is done by PECF process and role of mechanical honing is just to remove the passivating layer of metal oxide.

- Improvement in surface characteristics of straight bevel gears by PECH is highly dependent on the accuracy of the cathode gears used and on precision of completing the finishing operation by proper meshing of workpiece gear with the cathode gears and honing gear.

\section{Scope for future work}

- Use of PECH to finish of other gears of conical geometry such as spiral bevel gears and hypoid gears using the concept of complimentary cathode gears.

- Use of PECH for gear tooth profile modifications such as tooth profile modification, root relief, tip relief etc. by modifying the profile of cathode gears.

- Development of cathode gears for root relief, tip relief.

- Study of micro-chips removal from the workpiece gear during electrolysis process.

\section{Acknowledgement}

Authors acknowledge for help and support of Volvo Eicher Commercial Vehicles (VECV), Pithampur, Madhya Pradesh, India, for allowing us to use their facilities of surface roughness measurement.

\section{References}

Capello, G.; Bertoglio, S. (1979). A new approach by electrochemical finishing of hardened cylindrical gear tooth face, Annals of CIRP, 28 (1), 103-107

Datta, M.; Landolt, D. (1981). Electrochemical machining under pulsed current conditions, Electrochimica Acta, 26 (7), 899-907 
Pathak, S.; Jain, N. \& Palani, I. A.: Improving Surface Quality of Bevel Gears by ...

Fang, X.; Qu, N.; Zhang, Y.; Xu, Z.; \& Zhu, D. (2014). Effects of pulsating electrolyte flow in electrochemical machining, Journal of Materials Processing Technology, 214(1), 36-43

He, F.; Zhang, W.; \& Nezu, K. (2000). A precision machining of gears: slow scanning field controlled electrochemical honing, Japan Society of Mechanical Engineers International Journal Services, 43(2), 486-491

McGeough, J.A. (1974). Principles of electrochemical machining, Chapman and Hall, London

Misra, J.P.; Jain, N.K.; \& Jain, P.K. (2010). Investigations on precision finishing of helical gears by electrochemical honing process, Proceedings of IMechE, Part B: Journal of Engineering Manufacture, 224(12), 1817-1830

Misra, J.P.; Jain, P.K.; Jain, N.K.; \& Singh, H. (2012). Effects of electrolyte composit ion and temperature on precision finishing of spur gears by pulse electrochemical honing (PECH), International Journal of Precision Technology, 3(1), 37-50

Naik, L.R.; Jain, N.K.; \& Sharma, A.K. (2008). Investigation on precision finishing of spur gears by electrochemical honing, Proceedings of the $2^{\text {nd }}$ International and $23^{\text {rd }}$ AIMTDR Conference, IIT Madras, India, 509-514

Ning, M.; Xu, W.; Xuyue, W.; \& Zefei, W. (2011). Mathematical modeling for finishing tooth surfaces of spiral bevel gears using pulse electrochemical dissolution, International Journal of Advanced Manufacturing Technology 54, 979-986

Pathak, S.; Jain, N.K.; \& Palani, I.A. (2013). Methodology for precision finishing of conical gears using automated field controlled Electrochemical Honing process, Proceedings of $2^{\text {nd }}$ International Conference on Intelligent Robotics, Automation and Manufacturing 2013 (IRAM 2013), Dec. 16-18, 2013, IIT Indore (Eds. N K Jain, I A Palani, B K Lad, M S Kumar and A Parey), 440-449

Pathak, S.; Jain, N.K.; \& Palani, I.A. (2014a). On use of pulsed electrochemical honing to improve micro-geometry of bevel gears, Materials and Manufacturing Processes 29(12) Dec. 2014 (DOI: 10.1080/10426914.2014.952032)

Pathak, S.; Jain, N.K.; \& Palani, I.A. (2014b). Surface characterization of 20mncr5 alloy steel bevel gears finished by pulsed electrochemical honing process, submitted to Precision Engineering

Shaikh, J.H.; \& Jain, N.K. (2014). Modeling of material removal rate and surface roughness in finishing of straight bevel gears by electrochemical honing process, Journal of Materials Processing Technology, 214(2), 200-209

Shaikh, J.H.; \& Jain, N. K. (2013). High quality finishing of bevel gears by electrochemical honing, Chapter 41 in DAAAM International Scientific Book 2013, 697-710, B. Katalinic \& Z. Tekic (Eds.), Published by DAAAM International, ISBN 978-3-901509-94-0, ISSN 1726-9687

Wei, G.; Wang, Z.; \& Chen, C. (1987). Field controlled electrochemical honing of gears, Precision Engineering, 9(4), 218-221 